\title{
Confucian Humanistic Values of the Combination of "Human Being" and "Benevolence" and Fusion of National Cultures
}

\author{
Guo-li TANG ${ }^{1, ~}{ }^{*}$ and Hui-min XIE ${ }^{1}$ \\ ${ }^{1}$ Beijing University of Chemical Technology, China \\ "Corresponding author, Email: tanggl@mail.buct.edu.cn
}

Keywords: Confucian humanism, Values of the combination of "human being" and "benevolence", Fusion of national cultures.

\begin{abstract}
This essay discusses the Confucian humanistic values of the combination of "human being" and "benevolence", pointing out that Confucian humanistic values of the combination of "human being" and "benevolence" have introduced high, extensive, benevolent, modest, tolerant spiritual nature, which enabled the Chinese culture to possess a traditional spirit of cultural tolerance, cultural benefit and cultural equality since ancient civilizations.

Between native culture and foreign culture, multi-ethnic country in between various ethnic cultures, are due to cultural differences and made into a cultural exchange and collision, will therefore lead to cultural integration or cultural diaphragm. We need a culture inclusive and equitable approach to the understanding of traditional and contemporary ethnic cultural integration experience, but also need to eliminate ethnic conflicts by virtue of the diaphragm caused due to culture. Since ancient times Chinese culture has been the multi-ethnic cultural integration of community of Chinese culture as the main body, this community long-term preservation, not broken, the Chinese nation has always played a powerful role in promoting the spirit. "Toynbee lists the 21 civilizations in world history, which has 20 civilizations have ever been interrupted, only the Chinese civilization has never been interrupted, the Chinese culture is rich and developed continuously in this historic process, this unique historical conditions that other cultures do not have. "[1] (P3) Confucian culture and multi-ethnic cultural fusion took place close relationship, Confucianism Humanism "human being", "benevolence "unity values play an important influence on such Chinese culture and minority cultures together constitute the great tradition and little tradition of mutual benefit, interdependent community. To Study the existence of the multi national cultural fusion community, and understand the relationship between Chinese culture as the main body of culture and minority culture which are equal communicated, mutual effect and inclusive with each other have significant meaning on drawing lessons from history, improving national cultural fusion, realizing the cultural tradition in the contemporary society, and enhancing national unity in the view of scientific development.
\end{abstract}

\section{Cultural Functions and Cultural Integration}

Culture has a variety of functions, including the nature of the endosarc, difference, exchange, fusion, collision and disconnect. [2]Different peoples have different cultural connotations. Culture tradition is a national cultural tradition, a nation's value idea, ideal sentiment, thinking mode, a core strength of a nation's growth, and is also the fundamental factor to form the national differentiation.[3]Regardless of local and foreign culture, or the national culture, there are cultural differences between each other. Cultural differences, which determine the cultural characteristics of the 
exchange, and also determine the cultural differences in the impact of the characteristics of the disconnect. The cultural differences of characteristics make the culture has the the required functionality of excluding disconnect and enhancing integration. The culture's function is not inherent but it should be realized through the creation of people. Just from the subjective requirement of people's material creation, the culture becomes the performance of man's essence and the causes of the formation of human nature. People according to the subjective needs of material has created the culture, "create something and some ways to meet their own needs; In such a process of creation, it is the man himself to be shaped into a culture." [4](P77)The "man" is a collection of ethnic groups. the process of the growth of ethnic groups is the formation on the ethnic groups, "Culture is not only one-dimensional but also with the development forward; At the same time, different people of different ethnic groups have different characteristics in various conditions"; So, according to the demands of people (ethnic group) and different people (different ethnic groups), a variety of cultural functions come out. The variety of culture's functions is not an independent cultural phenomenon, but it has a close relationship with the cultural development of the nation. The "essence" of human's culture is to make people's demand form a kind of demand level from existence to enjoy, and then to self realization.[4](P77)"With the development of society, the need of people's self realization is becoming more and more prominent, so people become a culture gradually. The satisfaction of these needs creates various kinds of culture. In the same time, people themselves are more and more civilized". [4](P78)Civilized people and society are the goals of every ethnic group culture, and the target cannot be realized through self enclosed and disconnect; It must be through cultural integration of ethnic groups, and with national exchanges in the process of cultural tolerance. So, when many kinds of cultural functions are closely related to the development of national culture, the integration of culture becomes the core function of many kinds of cultural functions.

\section{Confucian Humanistic Values of the Combination of "human being" and "benevolence"}

In the Pre-Qin Confucian thought, in the spirit of the individual qualityreflected in the values of the combination of "human being" and "benevolence". The so-called the combination of "human being" and "benevolence" endosarc, both for people's consciousness of cultivating one's moral character, as reflected in the cultivation of the social practice. The combination of "human being" and "benevolence" is two practical links about people practice combined with practice. Doctrine of the Mean says" Benevolence is human being and its most obvious function is in love for relatives." [5](P28) Here the "benevolence" and "human being" are identical. ZhuXi notes: "people, in terms of itself. According to reasoning, people naturally have the meaning of compassion and love, you can discover when you deeply taste."[5](P29) To think "Benevolence" as "human" spiritual existence and the purpose of human's spiritual growth and development; "Therefore, the skillful handing of government is contingent upon having the right people. You attract the right people by your own character. You cultivate your character through the Tao and you manifest the Tao by means of benevolence."[5](P28)When a person through cultivation, start the inner spirit of goodness," human being" and "benevolence" integration.

Therefore, in the perspective of Confucian ideas, groups and societies, simple for an individual who is not enough, even if he (she) mastered the art of manual, do not 
know the fundamentals of life, can't integrate individuals into groups, will eventually lose the talent. So the spiritual mentor of Confucianism Confucius attached great importance to the individual person's "benevolence" of fundamental, pay attention to "human being" and "benevolence" combination. The Analects of Confucius, the philosopher You says, "They are few who, being filial and fraternal, are fond of offending against their superiors. There have been none, who, not liking to offend against their superiors, have been fond of stirring up confusion. The superior man committed his attention to what is radical. That being established, all practical courses naturally grow up. Actions about filial piety and fraternal submission are the root of all benevolence." $[5](\mathrm{P} 48)$ In this theory, " as human " of the " human " generally refers to the sense of "human", while studying, asked, "committed to radical" after "human" was referring to the " human", and " the benevolence " of the "human". Doctrine of the Mean says "There are five pervasive relationships in this world, which are carried out in three ways. The relationships are those between ruler and minister, father and son, husband and wife, elder brother and younger brother, and between friends .The three ways of practice are wisdom, benevolence and courage, but they are practiced in unison."[5](P29)Become the "human being" and "benevolence" combination, you can get the moral realm, into the moral category.

\section{Confucian Combination Values of "human being" and "benevolence" Have an Influence and Significance on Fusion of National Cultures}

Confucian culture points out the combination of "human being" and "benevolence", and the doctrine of "loyalty" and "forgiveness", which has features with lofty realm, broad mind, equal comity, incorporation." In the exchanges with other countries and nations, we should be friendly rather than destroy their countries and sweep wealth, which is so called' prosperity of countries to the brink of extinction, inherit the tradition will disappear, promote hermit's talent '.Judging from the history of the development process of Chinese culture, and most of the other incoming Chinese cultures can live together, learn and absorb each other."[1](P4)

\section{The Combination of "human being" and "benevolence" for Destiny and Morality}

Confucian combination of "human being" and "benevolence" have philosophical basis on orders from the world of nature, extended world by benevolence, for the world of mankind lives. The philosophical attitude of concerning the whole world's destiny makes man and nature in harmonious coexistence, noreligious person God opposite, makes Chinese culture have cultural tolerance of mind and heart at the beginning. From the crown abdication system in ancient times, we can see the interaction with people's destiny and morality. Rulers regard the dominant matter as "man of virtue" "mandate of heaven". The Book of History • Canon of Shun, records deeds about Yao hand over the crown to Shun, "searches the past thing. emperor Shun was named ChongHua, who assists the emperor Yao. He has a profound mind, temperature and civilization, respectful and honest. His potential morality uploads after the imperial court knows, emperor Yao bestows upon the position."'[6]Shun with "human being" and "benevolence" moral practice had been appreciated by emperor Yao, Yao would hand over the crown to Shun. Behind this political move crown abdication, to imply China the cultural meaning of humanism. In the understanding of the ancient sages, world nature in accordance with the reasonable and orderly order exists, its rationality and regularity is good of existence, morality of existence, the person is existing in the natural world, explore the world regulation and heaven and 
earth "benevolence", so cultivate "benevolence", implement "benevolence"; and great person with benevolence and morality, "abundant benevolence match with earth, virtue match heaven",[5](P35) so can administer a country and dominate people. TuWeiming talking about the Chinese philosophy of Confucian humanism, says: " at the beginning of Chinese philosophy is not marked by the original animism myth and religious break oriented to rational thinking, but marked by the destiny and human morality interaction type of moral discuss. As Pre-Confucian era classic The Book of Songs - Odes of Zhou records, BC 12 the virtues of the rise of civilization is the result of the Zhou dynasty:' lead feudal princes sacrifice emperor, sincerely devotion, pray for longevity, heaven bless for emperor has no limited boundaries. 'In order to keep in harmony with heaven and in search of well-being, concept of cultivation virtues provides a root metaphor for cultivation.'[7](P606-607) In fact, Confucian humanism reflect open mind and understanding of human nature; not closed themselves in the narrow confines of human society, but a reference to the laws of heaven and earth, search and discovery of the harmonious coexistence and symbiotic way. Therefore, occurred in ancient times political abdication, became the political model in the sense of cultural inclusion. Discussion on the relationship between nature and human, LaoZi - chapter twenty-five says:" Tao, heaven and earth is great, people is also great. Domain has four great things, and people take up one."[8] When the person is in the "great four" State create their cultural patterns, the pattern must have inclusive connotation.

\section{People-oriented Values of the Combination of "human being" and "benevolence"}

Rulers in the face of multiculturalism exist in ancient times, there have been historical experience to serve the community and reserve differences. Mencius says emperor Teng asked the relations problems between small countries and big powers, Mengzi uses previous Zhou emperor GugongDanfu analogy with the historical experience as answer. Mengzi says "Once previous Zhou emperor GugongDanfu bases in Bin, Di invades their territory. Serves them with money, not repelling Di intrusion; serves them with horses, not repelling Di intrusion; serves them with pearls, not repelling Di intrusion. So call in the older and listen: ' Di desires our land. I hear also, a gentleman not to harm with its dependants. Why do you worry about not having the monarch? I'm ready to leave.' So he leaves Bin, crosses mountain Liang, builds in the foot of a hill Qi. people in Bin says: ' for humanity, can't lose.' More and more people follow him in Qi as people in the market."[5](P225-226)Ancient land of barren expanse, Zhou cultivates land camp State in Bin, but not at the expense of war cling to Bin, "a gentleman should never to harm its dependants" courtesy Di, leave Bin destroys camp, establish other sites. Previous Zhou emperor GugongDanfu serves the "humane" things to do, wins the people recognition, "More and more people follow him in Qi as people in the market". This show "human being" and "benevolence" oneness of cultural values and cultural powers, indicating that ancient Zhou people is strong, is not strong on force powers, but strong in righteousness and justice powers, to lay the foundation for future generations of Chinese culture to "human being" and "benevolence" values attract many ethnic cultures integration.

\section{The Combination of "human being" and "benevolence" for Culture Tradition Equality and Interdependence}

The Chinese national culture with the spirit of Confucian humanism doesn't permit Han nationality culture to squeeze other national cultures. Meanwhile, the culture of the Han nationality and other ethnic cultures are not marked by the strong 
culture and the weak culture. On the contrary, in Confucian thought, it has always advocated cultural equality. The Analects of Confucius, the master says, "The men of former times in the matters of ceremonies and music were rustics, it is said, while the men of these latter times, in ceremonies and music, are accomplished gentlemen. If I have occasion to use those things, I follow the men of former times."[5](P124)Its culture is very equitable and open-minded. Zhu Xi quote Cheng $\mathrm{Zi}$ 's word criticism of the language of narrow-minded people culture, just as with "literary" and "plain" feature to distinguish between "cultivation" culture and "savage" culture, but is precisely the origin of the cultural, with "proper quality" traits. Zhu Xi says: "Cheng Zi says: ' The men of former times in the matters of ceremonies and music, literary and plain are harmonious, however, current people consider it as plain. While the men of these latter times, in ceremonies and music, literary surpass plain, however, current people consider it as gentility, thought the gentleman. '"The advanced cultural attitude in ancient time makes the culture of the so-called great and little traditional culture, elite and folk culture, elegant and popular culture coexistent and mutual support with close relations.

The great traditional culture penetrates into folk needs a ruling policy of a music education to guide, the little traditional culture is paid more attention through the way to absorb into the great needs the ruler of making music education has the cultural tolerant mind. From the history and culture, when rulers make ruling policy, they can take the exchange relationship into account, and aware that the ruling policy should be based on people's livelihood needs and make appropriate adjustments. The Book of Han records" Each year in early spring months, folk will be distributed to till the fields when collecting songs official shakes his large, wooden bells patrol on the road to the people collecting folk songs, give it to the imperial court musician, accompany by music, sing to the emperor. So wise monarchs do not drill into folk out and know that the world's people." [9] Governing by benevolence, a ruler should have a cultural consciousness over his administrating behavior.

Confucian humanism spirit is the traditional spirit of Chinese excellent culture. Its untied value of human and benevolence makes Confucian culture with spiritual essence lofty, extensive, benevolent, modest, inclusive. Doctrine of the Mean says "Therefore, fully actualized sincerity is ceaseless. Ceaseless, it is eternal. Eternal, it is apparent. Apparent, it is far-reaching. Far-reaching, it is vast and deep. Vast and deep, it is high and bright. Since it is vast and deep, it can support all things..... The way of Heaven and Earth can be perfectly expressed in a single phrase: "Its appearance as things is not repeated; therefore its production of things is unfathomable."[5](P34-35) When Confucian mention humanistic values of the combination of "human being" and "benevolence", they lay emphasis on practical activity of inner cultivation and external behavior. In the same time, they think experience and practice benevolence must have sincere heart and practical action, pursue benevolence in the world and achieve continuous self-improvement. Thus, the united value of human and benevolence is a kind of good value about the heaven and earth.

\section{References}

[1] Hong Lin, etc. Conflict and Integration of Chinese and Foreign Cultures. Jinan: Shandong University Press, 2010.

[2] Ya-biao Gao, etc. In the Depths of National Soul. Beijing: China Federation of Literary and Art Circles Publishing Corporation, 1988: 1-4. 
[3] Pu Pang. Culture of Nationality and Contemporaneity. Beijing: China Peace Publishing Press, 1988:162-163.

[4] Pu Pang. Pang Pu Anthology (volume III).Jinan: Shandong University Press, 2005.

[5] [Song]Xi Zhu compiles. Variorum of the Four Books. Beijing: Zhonghua Book Company, 2012.

[6] Min Li etc, compiles. The Book of History with Translation and Annotation. Shanghai: Shanghai Ancient Books Publishing Press, 2000:12.

[7] TuWeiming. TuWeimingAnthology(volumeIV). Wuhan: Wuhan Publishing Press, 2002.

[8] Gu-ying Chen. LaoZi Notes and Review. Beijing: Zhonghua Book Company, 1984:163.

[9] [Han]GuBan. The Book of Han. Beijing: Zhonghua Book Company, 1999 : 947. 